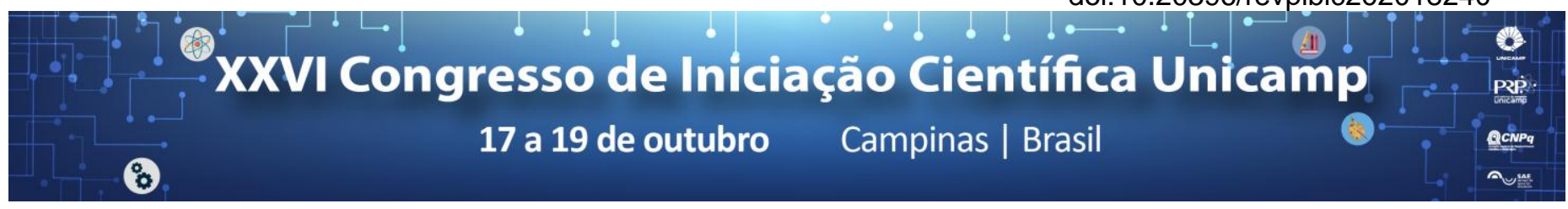

\title{
Simulação Monte Carlo do Fator de Retroespalhamento em Mamografia Digital
}

\section{Bruno L. Rodrigues*, Alessandra Tomal.}

\section{Resumo}

O exame de mamografia é uma técnica de radiodiagnóstico amplamente utilizada para a detecção e identificação de lesões na mama. O protocolo brasileiro de controle de qualidade sugere que a dose em mamografia deve ser estimada através da dose de entrada na pele (DEP). Dentre os fatores mais importantes para a estimativa do DEP está o Fator de Retroespalhamento (BSF), que é tabelado para qualidades do feixe utilizados em equipamentos de mamografia telafilme. Este trabalho tem como objetivo estabelecer uma metodologia para a determinação do BSF para as principais combinações ânodo/filtro empregadas em equipamentos contemporâneos de mamografia digital.

\section{Palavras-chave:}

Mamografia, Retroespalhamento, Monte-Carlo

\section{Introdução}

O exame de mamografia se consolidou como a principal técnica para a identificação precoce do câncer de mama. Por utilizar radiação ionizante, a dose absorvida pelos tecidos é alvo de muita atenção e preocupação. A dose glandular é a grandeza mais adequada para avaliar a dose absorvida pela mama, contudo, sua quantificação é impossível experimentalmente, sendo normalmente obtida através de aproximações ou simulações computacionais. O protocolo brasileiro de controle de qualidade [1] sugere que a avaliação dosimétrica em mamografia seja realizada através da determinação da Dose de entrada na Pele, que é obtido através do Kerma no ar e do fator de retroespalhamento (BSF). O BSF é referenciado na literatura apenas para espectros mais comuns, produzidos pelas combinações anodo/filtro $\mathrm{Mo} / \mathrm{Mo}, \mathrm{Mo} / \mathrm{Rh}$ e $\mathrm{Rh} / \mathrm{Rh}$ usados em equipamentos telafilme. Com novas tecnologias de imagem, espectros produzidos por ânodos de tungstênio são cada vez mais comuns, havendo necessidade de estabelecer uma metodologia capaz de obter o BSF para espectros de raios $X$ contemporâneos. Este trabalho tem como objetivo estabelecer este método de quantificação.

\section{Resultados e Discussão}

Foi utilizado o código Monte Carlo Penelope v.2014 para modelar computacionalmente as configurações de um exame de mamografia. Para simular a mama comprimida foi utilizado um modelo semicilíndrico de raio de $80 \mathrm{~mm}$, com espessura variando entre 45 e $80 \mathrm{~mm}$, sendo composto complemente por PMMA (Polimetilmetacrilato). A fonte foi modelada como pontual à $65 \mathrm{~cm}$ da base da mama, e foram consideradas cinco tensões de pico variando entre 25 e $35 \mathrm{kVp}$. Além disso foram considerados quatro combinações ânodo/filtro: Mo/Mo, $\mathrm{Mo} / \mathrm{Rh}, \mathrm{W} / \mathrm{Rh}$ e W/Ag. Para medir a dose foi modelado um pequeno volume de fluoreto de lítio $\left(4 \times 4 \times 1 \mathrm{~mm}^{3}\right)$, simulando um detector termoluminescente (TLD) na superfície do modelo cilíndrico. Devido às pequenas dimensões do detector, foram utilizados métodos de otimização e redução de variância para redução das incertezas estatísticas. Foram realizadas simulações com e sem o volume de PMMA. O BSF foi determinado através da razão das doses medidas no TLD com e sem a presença do objeto simulador de mama [2]. Os resultados obtidos foram analisados em relação à camada semirredutora (CSR), e estão ilustrados na
Figura 1 juntamente com valores de referência do European Protocol on Dosimetry in Mammography [3]. O fator de retroespalhamento varia de forma praticamente linear com a camada semirredutora. Cada combinação ânodo/filtro engloba um diferente intervalo de CSR. O máximo desvio, entre a referência e os resultados, foi de $0,3 \%$. Foram observados desvios maiores para conforme o aumento da CSR, principalmente para as combinações ânodo/filtro contemporâneas W/Rh e W/Ag.

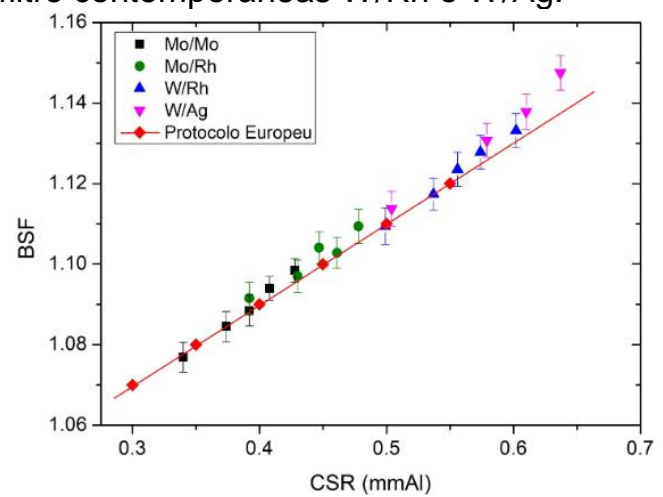

Figura 1. Resultados de simulação para o BSF.

\section{Conclusões}

A metodologia desenvolvida foi validada e é considerada adequada para estimar com precisão o fator de retroespalhamento, sendo uma ferramenta simples e de fácil reprodução. A necessidade de precisão deve ser sempre considerada na otimização da simulação, principalmente para tornar o estudo mais dinâmico. De forma geral a metodologia apresentou alto desempenho, possibilitando correções mais precisas de dose.

\section{Agradecimentos}

Os autores agradecem a PRP/FAEPEX/Unicamp, CNPq e FAPESP pelo apoio financeiro concedido.

${ }^{1}$ Brasil. Desempenho de Equipamentos e Segurança. Ministério da Saúde. Agência Nacional de Vigilância Sanitária. 2005. 104.p.

${ }^{2}$ Kramer R, et al. Backscatter factors for mammography calculated with Monte Carlo methods. Physics in Medicine and Biology. 2001;46(3):771-781.

${ }^{3}$ European Comission. European protocolo on dosimetry in mammography. Luxembourg: Office for Official Publications of the European Communities. 1996 ; 